cent. But that record was obtained in a series of $\mathbf{4 7 5}$ unselected cases, and in 103 of them chosen as suitable for the galvano-cautery we obtained 64.08 per cent. of cures." When, therefore, we study the cures resulting in the twenty-four out of thirty-two cases submitted to light treatment we must consider the other factors which were at work. (a) All the cures were in patients selected as "favourable" as regards both local and general conditions. (b) In certain cases no improvement was seen after a trial, sometimes extending over five months, with the regular use of a bath of as much as thirty minutes' duration, given daily except on Sunday. (c) In several instances the baths had to be abandoned owing to loss of weight, or to their being followed by pyrexia or fatigue. (d) Healing took place later, in some cases three months and longer after the light had been discontinued. (Figs. 1 and 2.) (e) In eleven cases there was no improvement, or progress was so slow that the galvano-cautery was employed; healing was then secured in all the eleven cases. (Figs. 3, 4, and 5.) (One case had, in addition, an artificial pneumothorax.) (f) In three cases an artificial pneumothorax was performed. We have previously shown that a well-marked case of laryngeal tuberculosis, unaltered or worse after some months of silence, may be completely healed three months after the performance of an artificial pneumothorax. ${ }^{3}$ $(g)$ Deducting all such cases, we find that there were only seven out of the twenty-four cures in which, in addition to sanatorium regime and voice rest, light was the only other treatment.

\section{Test Cases}

The most rapid healing occurred in three months. The patient was a woman of 41 , with a unilateral pulmonary lesion, chiefly pleuritic. (Fig. 6.) In the second case a cure was effected in five months-not a rapid result. The patient was on whispers all the time (there was no voice change), the lesion being a limited interarytenoid deposit. The third case was well in four months. The laryngeal lesion was limited, superficial, and one-sided, but the patient lost weight while undergoing the treatment, and his larynx relapsed afterwards. The treatment appeared to suit the larynx in the fourth case ; it was healed in six months, but the patient lost weight, and left to have a pneumothorax performed elsewhere.

The larynx had not healed at the end of four months in the fifth case, a man of 32 , with an irregular interarytenoid deposit, although tubercle bacilli had disappeared from his sputum, and his pulmonary signs (chiefly pleuritic) showed arrest. Three months later the larynx was clear. In the sixth case, a man of 56 , only the epiglottis was affected with a lupoid infiltration. The disease was still present after six months of light treatment, although tubercle bacilli had disappeared and the lung disease was arrested. Four months later, without further treatment, the epiglottis had healed. The seventh case was also a lupoid case. The patient soon lost his tubercle bacilli, and left the sanatorium at the end of five months with the larynx much improved. Three months later it. was healed, but the laryngeal disease recurred two years later, and again healed, this time without light baths or treatment other than voice rest and sanatorium regime. (Fig. 7.)

\section{Conclusion}

In thirty-two favourable cases there were no striking evidences of benefit from light treatment; in only two or three might some help from it be claimed. Nor can it be said that healing of laryngeal tuberculosis was hastened, or that the course of light baths in any way rendered subsequent cure by the cautery more rapid or more certain. Quite as good results have been obtained, and just as swiftly, with voice rest, sometimes supple- mented with the galvano-cautery or artificial pneumothorax, and, in all cases, the sanatorium regime.

The whole picture of tuberculosis is so remarkably changed for the better under sanatorium conditions that many remedies which appear to be beneficial under ordinary hospital or home conditions are found to add nothing to the improvement wrought by hygienic living in unvitiated air. Hence the number of "negative findings " with many new remedies when tried in a sanatorium. Under other conditions it is possible they may be of help-by suggestion if not otherwise. The constant medical supervision and control available at Midhurst has enabled us to see the possible drawbacks, and even dangers, of light treatment if not carefully and regularly watched. Since the above series was ended in November, 1929, we have continued to try this remedy in well-selected cases, and the conclusion still is that, while it may appear to be of help in a very few cases, it probably acts only by suggestion; that it is fraught with danger if not scrupulously supervised; and that, on the whole, in patients in a well-ordered sanatorium it is no addition to the treatment at present in use.

\section{REFERFNCES}

'Thomson, StClair: Tuberculosis of the Larynx: Ten Years' Sanatorium Experience, H.M. Stationery Office, 1924

2 Idem: Tuberculosis of the Larynx: Treatment with the GalvanoCautery, Lancet, 1926, i, 1084.

3 Thomson, StClair, and Trail, R. R.: Tuberculosis of the Larynx and Artificial Pneumothorax, Lancet, 1927, i, 963.

\section{THE RADIOTHERAPY OF CARCINOMA OF THE UTERUS *}

With Especial Reference to $X$-Ray Treatment BY

PROFESSOR FRIEDRICH VOLTZ

PRINCIPAL OF THE RADIOLOGICAL INSTITUTE, UNIVERSITÄTSFRACENKLINIK, MUNICH

I am exceedingly happy to have the honour of addressing this Section of the British Medical Association on the occasion of its Centenary Meeting, and I should like to express my heartiest thanks. I fully realize that the honour done to myself is a recognition of the work of the gynaecological clinic of Munich University and of its Director, Professor Albert Döderlein. This work has opened up new avenues in the radiotherapy of uterine carcinoma, and its value has been acknowledged in the appointment of the clinic to serve, with the Radiumhemmet of Stockholm and the Institut du Radium of Paris, on the Commission appointed by the Hygiene Section of the League of Nations to study the radiological treatment of carcinoma.

A. Döderlein made the first attempt on these lines in 1903, when he endeavoured unsuccessfully to cure inoperable carcinomata of the uterus with a preparation of radium. Since 1912 he has treated every patient admitted to the clinic by radiotherapy alone, and has entirely given up the radical operation. The number of cases of carcinoma of the uterus treated in the succeeding twenty years has amounted to 3,000 , and his experience with these large numbers has enabled him to assert definitely that radiological treatment does everything that radical surgery can do, while it is less dangerous and less drastic ; moreover, it can be of use where operation is impossible. As a result of his experience Döderlein has written :

" I have long maintained that the day of the dangerous and drastic radical operation is over. If it is possible to treat women by a much simpler, a safe, and a painless method, with as much prospect of success, this method must be given preference over the knife."

* Read in opening a discussion in the Section of Obstetrics and Gynaecology at the Centenary Meeting of the British Medical
Association, London, 1932. 
Since, as I have said, I regard my selection for this task as an honour done to the clinic and a recognition of the value of its work, I ask leave to base my paper on the results and methods of the Radiological Institute of the clinic, touching on the results and methods of other workers only for the sake of completeness.

\section{What Radiotherapy Alone Can Do}

I will start with the question: What can radiotherapy by itself achieve in carcinoma of the uterus? My answer to this question is based on 1,973 cases of uterine carcinoma. All these patients have been under observation for periods of between five and twenty years, and during the last few months the material has been thoroughly checked through. The data available for each case are, therefore, statistically unexceptionable, a fact of extreme importance if the statistics themselves and the deductions based on them are to be of any value.

\section{Cervical Carcinoma}

From 1913 to 1926 inclusive 1,866 cases of cervical carcinoma were admitted to the clinic. Of these, 143, or 7.7 per cent., were not treated, most of them because they were quite hopeless, sometimes moribund, and some of them because they would not submit to the treatment prescribed and preferred to go elsewhere. For statistical purposes, therefore, and in order to assess the results of radiotherapy, the number of cases is 1,723 . Of these 1,723 cases, 319 patients were alive and well after five years. The absolute cure figure is therefore 18.5 per cent. Table I shows their classification according to Döderlein's four groups, which have been recognized and adopted by the Radiological Commission of the Hygiene Section of the League of Nations as a basis for statistical investigations in this field.

\begin{tabular}{lc|c|c|c}
\multicolumn{1}{c}{ TABLE I } \\
\hline Group & & $\begin{array}{c}\text { Number in } \\
\text { Group }\end{array}$ & $\begin{array}{c}\text { Number of } \\
\text { 5-year Cures }\end{array}$ & Percentage \\
\hline Group 1 (operable cases)... & $\ldots$ & 326 & 141 & 43.2 \\
Group 2 (borderline cases) & $\ldots$ & 401 & 90 & 22.5 \\
Group 3 (inoperable cases) & $\ldots$ & 672 & 81 & 12.1 \\
Group 4 (“incurable" cases) & $\ldots$ & 324 & 7 & 2.1 \\
\hline
\end{tabular}

As the period under review includes the beginning, development, and perfection of the radiological technique, I consider that these results, especially the figures of 1924-6, represent accurately the present-day possibilities of radiotherapy of carcinoma of the cervix. This is especially true since all material was treated on a uniform system.

During the three years 1924-6, 418 cases of cervical carcinoma were admitted to the clinic. Fourteen of these, or 3.3 per cent., were not treated, for the same reasons as those given for the 143 untreated cases in the whole group. The number of cases available for statistical purposes is therefore 404 . Of these, 97 patients, or 24 per cent., were alive and well after five years. Table II gives their classification into Döderlein's groups.

\begin{tabular}{cc|c|c|c} 
Group & & $\begin{array}{c}\text { Number in } \\
\text { Group) }\end{array}$ & $\begin{array}{c}\text { Number of } \\
\text { 5-year Cures }\end{array}$ & Percentage \\
\hline Group 1 (operable cases)... & $\ldots$ & 99 & 49 & 49.4 \\
Group 2 (borderline cases) & $\ldots$ & 91 & 21 & 23.1 \\
Group 3 (inoperable cases) & $\ldots$ & 123 & 23 & 17.9 \\
Group 4 ("incurable" cases) & $\ldots$ & 85 & 4 & 4.9 \\
\hline
\end{tabular}

\section{Comparison with Operation Figures}

I will now compare the cure rates in the cases treated in the years 1924-6 with the figures obtained by J. Heyman of Stockholm, from a study of all the available literature, for the results of operation. The cure rate for the whole of the material was 24 per cent.; for Group 1, 49.4 per cent., and for Groups 1' and 2 combined (operable and borderline together), 37 per cent. For operated cases the absolute cure figures is 19.1 per cent., and the relative cure figure is $\mathbf{3 5 . 6}$ per cent. The conclusion therefore seems justified that in carcinoma of the cervix exclusive radiotherapy is the only method worthy of consideration, and should be employed in every case. In the words of Döderlein, the day of radical operation for cervical carcinoma is over. This conclusion seems even more strongly justified if the following considerations are taken into account: (1) Döderlein's figures from the clinic show a primary mortality from radiotherapy of 0.8 per cent. ; Heyman's figures for radical operation show a primary mortality of 17.2 per cent. (2) Radiotherapy in Group 3, consisting of undoubtedly inoperable cases, gave a five-year cure rate of 17.9 per cent., and in Group 4, consisting of "incurable " cases, one of 4.9 per cent. : every one of these patients would otherwise have died. (3) The percentage of cases which can be treated by radiotherapy is 96.7 , while an average figure of operability in cervical carcinoma, compiled from all the available literature, is only 64 .

\section{Carcinoma of the Body of the Uterus}

During the years 1913-26 inclusive 107 cases of carcinoma of the corpus uteri were admitted to the clinic and treated with radiotherapy alone. Of these 107 patients, 49 , or 45.8 per cent., were alive and well after five years. These cases can be divided into two groups: $A$, operable ; and B, undoubtedly inoperable. The fiveyear cure rate in Group A was 66 per cent. (43 cases out of 65), and in Group B 14.3 per cent. (6 cases out of 42). In order to show what the more recent methods of treatment can do $I$ will give the results in cases treated during the period $1921-6$ on a uniform system. The number of patients admitted with carcinoma of the body of the uterus and treated by radiotherapy alone was 39 ; of these, 24 , or 62 per cent., were alive and well after five years.

\section{Comparison with Operative Figures}

A comparison between the cure rate for all the cases admitted in 1913-26 (45.8 per cent.), for all the cases admitted in 1921-6 (62 per cent.), and for Group A, the operable cases, over the long period (66 per cent.), and Heyman's average cure figures for radical operation $\mathbf{( 4 2 . 8}$ per cent. absolute and $\mathbf{5 6 . 8}$ per cent. relative), makes it absolutely clear that the results of radiotherapy alone in carcinoma of the corpus uteri are commensurable with those of the radical operation. The figures of the clinic therefore confirm the opinion which Heyman formed on his experience with radium treatment in the. Stockholm Radiumhemmet :

"Our figures indicate infallibly that radiotherapy can give just as good results as operation; in view of our results we cannot agree with the almost universal opinion that radiological treatment of carcinoma of the body of the uterus cannot compete with surgical treatment."

Two further points for consideration are: (1) the primary mortality from radiotherapy is 0.3 per cent. as against the 10 per cent. of radical surgery, and (2) all the cases treated radiologically can be brought forward in evidence. These figures justify the treatment of all cases of carcinoma of the uterus by radiotherapy alone, and make it permissible to put a second question: Under what conditions can such results be obtained? 


\section{Treatment at Munich}

The following remarks are based on the experience and work of the Radiological Institute of the clinic. Dr. Lacassagne, from Paris, is dealing with radium treatment in another paper.

In order to obtain from radiotherapy results such as I have outlined, the following requirements must be fulfilled: (1) adequate means of applying treatment, adapted to modern radiological technique ; (2) a system of treatment designed to fulfil its specific purpose ; and (3) an administrative mechanism adapted to the needs of the treatment. There are, therefore, three classes of requirements: those connected with technique, with system, and with organization.

\section{Technique, Apparatus, and Personnel}

The technical bases of radiotherapy in the clinic are: (1) sufficient quantities of radioactive substances (at least. $100 \mathrm{mg}$. of radium element per case) ; (2) efficient and modern $x$-ray apparatus ; (3) every modern device for exact dosage; and (4) well-trained and reliable personnel. These four requirements must be adequately fulfilled if radiotherapy of uterine carcinoma is to give the results which I have shown it can give. As a member of the Radiological Commission I have had the opportunity of studying this question particularly closely, and have seen that when these conditions are thoroughly fulfilled the results are obtained. The figures of the Institut du Radium and the Radiumhemmet, besides our own, are a proof of this fact.

All cases of uterine carcinoma in the Radiological Institute are treated by a combination of radium and $x$ rays. We possess $1,500 \mathrm{mg}$. of radium element distributed, as in Paris and Stockholm, over a large number of small containers, of which the average capacity is $10 \mathrm{mg}$. ; these can be made up into applicators of any desired shape. We also possess three efficient modern $x$-ray installations with six treatment couches. Some of the tubes are enclosed in high-tension-proof and ray-proof lead casings; others are the modern type of metal-cased tube, with their own protection against leakage of high-tension current and radiations, on a special therapy mounting. The tubes are fed with rectified current from stabilivolt apparatus at a tension of $200 \mathrm{kV}$ and a tube current of $2.5 \mathrm{~mA}$. The patient lies on a special table which can be raised and lowered by an oil pump. She can be put in any desired position relative to the tube, and any desired field can be irradiated with absolute accuracy. It is essential in $x$-ray therapy of uterine carcinoma to give an exact dosage. We are now using recording dosimeters which allow the dose to be read off in $r$ units.

It is essential not to underrate the necessity for a reliable personnel. This is an important factor in the success of $x$-ray therapy, because the staff look after the apparatus, read the measuring and recording instruments, and regulate the tubes-are, in fact, in charge of all the factors which ensure that a correct dosage is given.

\section{Therapy. According to Plan}

Systematic treatment, the second condition for successful radiotherapy, comprises two factors: (1) the compilation of a plan of treatment suitable for the individual case, and (2) the consistent execution of the plan. Nowadays, when a patient is admitted, we lay down the exact lines on which she is to be treated. In its present form this " treatment scheme" embodies the experience of the last eight years, and is an important factor in success. In Munich we use a combination of $x$ rays and radium in multiple doses, but in Paris a single dose is given, and the whole treatment is carried out in the shortest possible time. As a rule we give a case of uterine carcinoma two courses of treatment separated by an interval of eight weeks.

Assuming that the clinical evidence is clear, the first treatment is carried out on the following lines:

1st day: Preparatory measures.

2nd day: Preliminary irradiation of the pituitary.

3rd day: $X$-ray treatment, including, when necessary, sensitizing treatment.

4th day: Rest, prolonged over the following days when necessary.

5th day: Diagnostic operative measures.

6th day: Rest, prolonged if necessary.

7th day: Radium treatment.

8th day: Rest, prolonged if necessary.

9th day: Discharge.

When a patient is discharged from the clinic she is handed over again to her family doctor, who is given detailed instructions for her treatment in the interval before she comes back to the clinic, and ensures that the rules laid down for her conduct on discharge shall really be carried out. This treatment is naturally confined to tonic measures, directed to improving her general condition. Eight weeks after the end of the first course of treatment the patient comes back to the clinic for a second course, the scheme of which is as follows:

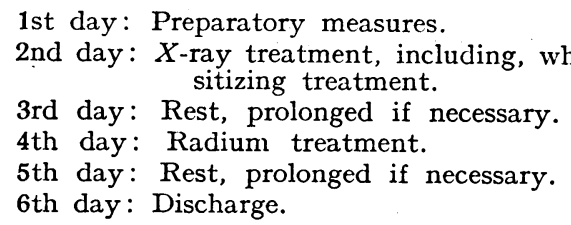
sitizing treatment.

3rd day: Rest, prolonged if necessary.

4th day: Radium treatment.

5th day: Rest, prolonged if necessary.

6th day: Discharge.

After the second course the patient attends the clinic repeatedly for control and observation. During the first year she comes every two months; during the second year, every three months; and thereafter, every six months. If it is found necessary to give more treatment, a new treatment scheme is drawn up, which includes radium treatment, $x$-ray treatment, or both, according to the needs of the case.

I mentioned in describing the scheme of the first course of treatment that it was carried out in that form when the clinical evidence was clear. The diagnostic operative measures, including scraping and probe excision, are carried out after $x$-ray treatment for the same reasons that preliminary irradiation is given before, and radium treatment after, the radical operation-in order to damage the carcinoma as much as possible and to minimize the risk of spreading the disease by the operative measures.

\section{Routine Irradiation of the Pituitary}

The scheme for the first course of treatment includes a preliminary irradiation of the pituitary. This measure is based on the work of Hirsch and Hofbauer. Hirsch considers that it improves the general condition by stimulating the function of one of the members of the endocrine chain, and Hofbauer believes that it increases the sensitivity of the carcinomatous tissue. Since 1923, when Hofbauer put forward this suggestion, we have carried out this preliminary treatment in all our cases of uterine carcinoma. We have seen no untoward effects, and the improvement in the general condition of the patient is very striking. The weight curve, which is an expression of the patient's general condition, follows a characteristic course during radiation treatment quite apart from the effect on the pituitary.

When radiotherapy is successful the weight increases immediately after the treatment; after radical operation the rise is slow and only begins after a long period of convalescence.

Pituitary irradiation is carried out through two fields. These are plotted on each temple in such a position that 
the central ray of the beam passes through the sella turcica. The area of the pituitary field is $6 \times 8 \mathrm{~cm}$., or $48 \mathrm{sq} . \mathrm{cm}$. The focal skin distance is $30 \mathrm{~cm}$., tension $200 \mathrm{kV}$, current $2.5 \mathrm{~mA}$, and filtration $1 \mathrm{~mm}$. copper. Each temporal field is given 30 per cent. of an erythema dose, and under these working conditions about 25 per cent. of an erythema dose reaches the pituitary. The pituitary is only irradiated once, during the first course.

\section{$X$-Ray Treatment}

If the normal scheme of treatment is being carried out the pituitary irradiation is followed by the $x$-ray treatment. In normal cases this is given by the " large-field " method, in which the whole pelvis is irradiated through a large field on the abdomen and another on the back. In the majority of cases the size of the fields is $10 \times 15 \mathrm{~cm}$., or $150 \mathrm{sq} . \mathrm{cm}$. On very fat women it is sometimes enlarged to $15 \times 20 \mathrm{~cm}$. (300 sq. cm.), or two contiguous fields are used both anteriorly and posteriorly instead of one, giving an effective area of $20 \times 30 \mathrm{~cm}$., or $600 \mathrm{sq} . \mathrm{cm}$. The other working conditions are: 40 to $50 \mathrm{~cm}$. focal skin distance, $200 \mathrm{kV}, 2.5 \mathrm{~mA}$, and $1 \mathrm{~mm}$. copper.

\section{Dosage}

In 1918 Seitz and Wintz introduced the conception of a " carcinoma dose" into the $x$-ray treatment of carcinoma. This idea opened up a new line in the radiotherapy of uterine carcinoma, because their work showed that success depended upon giving a definite and accurately measured dose, and that the optimum dose was between 90 and 110 per cent. of the " unit skin dose" (H.E.D.) which they laid down as a dosnge unit. Their investigations have been confirmed by our experience on this abundant material. It is essential for success that treatment should be carried out with all the necessary technical resources, and that an exact dosage should be given. Our observations and experience show that the carcinoma dose laid down by Seitz and Wintz fourteen years ago-and so hotly disputed-probably needs correction by what I may call histological or biological coefficients, but it is none the less certain that there is an optimum dose for each individual form of uterine carcinoma. As a proof of the validity of this principle, we know that some forms of uterine carcinoma-for example, adenomatous carcinoma of the cervix-do not respond so well to a given dose as others. This is, however, an unsolved problem on which no definite judgement can be passed, and it is outside the scope of this paper. One thing is certain: that the achievement of good results with radiotherapy of uterine carcinoma is a problem of biological physics-that is, it consists in applying to a given parb of the body an optimum dose of radiant energy. Döderlein has been an exponent of this belief since radiotherapy was first commenced in 1913, and has recently expressed it with even greater emphasis. Our aim is, therefore, by the application of $x$ rays through large fields and by the subsequent radium treatment of the uterus, to give a definite minimal dose of 90 to 110 per cent. of the unit skin dose.

\section{The Erlangen Method of Pure $X$-ray Treatment}

Although we hold, as a result of our experience in the clinic, that the combined treatment of uterine carcinoma with $x$ rays and radiation is the metiod of election, chiefly because it offers the greatest facilities for adjusting the dose to the individual, I must touch shortly on treatment by $x$ rays alone-more especially as $\mathrm{I}$ have headed my paper, "With especial reference to $x$-ray treatment."

The great development and perfecting in Germany of pure $x$-ray treatment was a result of circumstances. During the war Germany was entirely cut off from the outside world, and, owing to the inflation of the mark, was unable to purchase large supplies of radium. Only a few clinics, one of which was our own, possessed adequate quantities of radioactive substances. The pure $x$-ray treatment of carcinoma of the uterus is based on the work of Seitz and Wintz. Both started on the assumption that it was possible by appropriate methods of irradiation to apply to the uterus a dose of $x$ rays sufficient to destroy the carcinoma, and from this assumption and their consequent investigations they evolved the " Erlangen " method. Their work was assisted by the development of $x$-ray technique and the improvement in the efficiency of $x$-ray apparatus and tubes.

The fields are irradiated one by one in such a direction that the beams cross at the uterus; the sum of the energy supplied by the six applications gives the required minimal dose of 90 to 110 per cent. of the unit skin dose.

The successes achieved by Wintz at the Erlangen clinic show that this method, a product of the abnormal conditions of its time, can give excellent results if properly carried out. The absolute five-year cure rate for cases of cancer of the cervix treated during the years 1915-26 was 19.5 per cent. ; for those treated in the years 1921-6 it was 20.9 per cent. These results are comparable with those we have obtained by our combined treatment. For carcinoma of the body his absolute cure rate for the years 1915-26 is 42.7 per cent., and for the years $1921-6$ it is 50.5 per cent. These figures are also about the same as ours.

These are the results obtainable with pure $x$-ray treatment, but to achieve them it is naturally essential that the technique of treatment should be thoroughly learnt and carefully carried out.

\section{Diagnostic Operative Measures}

These measures include excision and scraping. From every case of uterine carcinoma we take a specimen for microscopical examination in order that the clinical diagnosis of carcinoma may be confirmed histologically, and in order to prove after cure that the disease really was a carcinoma. Another measure carried out after $x$-ray treatment is fulguration and coagulation with the highfrequency current. This is especially valuable as an auxiliary method of treatment in cauliflower carcinomata of the portio vaginalis, and in infiltrating medullary carcinoma ; their object is to intensify the local action of the rays. We have never seen any untoward results from them, although the crater in the cauliflower carcinoma of the portio vaginalis is sometimes very deef. On the contrary, the rapidity with which the destroyed tissue is replaced is a constant source of surprise. At the beginning we only employed this treatment in bad cases, but the good results we obtained have induced us during the last few years to carry it out in borderline and operable cases also. We propose to make even more extensive use of it in the future, for we believe that its effect on the deep tissues gives considerable assistance to radiotherapeutic measures.

\section{Radium Treatment}

Treatment with radium is carried out two days after the diagnostic operative measures. As Dr. Lacassagne is dealing with this subject very thoroughly in his paper, I will not discuss it here. I will just mention that our method is designed to fit into our general scheme of treatment. We give the vaginal, cervical, or intrauterine applications twice, once in each course of treatment. Each application consists on the average of $55 \mathrm{mg}$. radium element, and the radium is left in place for twenty-four hours. The filtration is through $1 \mathrm{~mm}$. of brass. For carcinoma of the cervix we use vaginal and cervical applicators, and for carcinoma of the body intrauterine applicators. For vaginal application we use disk-shaped 
containers embedded in a cork carrier. The vaginal and intracervical applications necessary in carcinomata of the portio vaginalis are carried out at the same time, occasionally on two consecutive days. The second course, which also includes $x$-ray and radium treatment, is carried out after an interval of eight weeks. The irradiation is again calculated to provide a minimal dose of 90 to 110 per cent. of the unit skin dose.

\section{Results of the Scheme}

This, generally speaking, concludes the scheme of treatment in carcinoma of the uterus. Further treatment is only carried out when special circumstances make it necessary, and an interval of twelve weeks is allowed from the end of the second course. We lay great stress on the necessity for the patient herself to co-operate in the scheme we lay down, and we enlist the help of the doctor who has sent her to the clinic.

Our records show that, if the scheme is consistently carried out, the cure rate in Group 1 (operable) can be raised from 49 to 58 per cent., and in Group 2 (borderline) from 23 to 29 per cent. The reason is that many patients, a few weeks after the end of the first course, feel " well" and do not come back for the second; accordingly, when they do come back, their condition is much worse and the prospects of a cure are diminished. There is, however, another and greater reason why the figures are not as high as they might be, and that is the abnormal economic conditions from which Germany is suffering at the present moment. Many patients are quite unable for purely financial reasons to come back to the clinic for the second course.

\section{Administration : After-Care : Record-Keeping}

The essential administrative requirements are: regular execution of treatment and subsequent examination, and the education of the patient to regularity ; (2) suitable provision for controlling regular treatment and subsequent observation ; (3) careful statistical record and control of all clinical materal. These administrative requirements are just as important as those of technique and system, and if they are fulfilled exactly the work is much facilitated. They make possible a systematic control of the clinical material, and thus contribute markedly to success.

I have already spoken of the importance of regularity in treatment, and how it contributes to the results. Regularity in after-observation is equally important in order to detect recurrence and ensure that fresh treatment is carried out in good time. I have also remarked on the necessity of educating the patient to conform to this regularity. It so often happens that, when a patient's subjective distress and haemorrhage cease, she regards her instructions as an unnecessary compulsion imposed for purely scientific reasons. On account of this I think it is not out of place to say a word or two about the administrative measures by which we achieve this regularity, which is necessary purely in the interests of the patient, and which has certainly contributed to the improvement of our results.

\section{Follow-up Measures}

Every new patient receives, at the conclusion of the first course of treatment, a treatment card showing her name, index number, date of treatment, the date on which she is to return for her second course, and the dates on which she should present herself for subsequent observation. They serve the double purpose of informing the doctor of the arrangements and of impressing upon the patient the necessity for keeping exactly to her appointments. At the same time each patient is given a leaflet setting out all her rules for conduct. We have recently had to enlarge and tighten it up, for we have often known doctors, in the interval between the two courses of aftertreatment, disregard instructions to the great danger of the patient.

The clinical material is kept under permanent control by means of a special chronological card index. This is necessary to ensure good results and the sound development of therapeutic methods, and serves as a check on whether patients have actually carried out their instructions. If a patient, in spite of every warning, does not appear on the appointed day for further treatment or observation, a letter is written to her warning her that it is absolutely essential to keep to her times. If a patient fails to reply to two of these warnings, which are accompanied by a stamped addressed envelope, or if the letter is returned through the dead letter office, inquiries are made through the local authorities to discover whether the patient has gone away, and, if so, where. If she has died, we ask for the date and cause of death. We have now carried out these follow-up measures for some years, and have succeeded in establishing a permanent control and also in improving our figures. The number of patients failing to attend or who are lost sight of is very much smaller nowadays than it used to be. The chief difficulties, which affect many patients, are to be found in the economic and social conditions of the times.

Administrative measures include the keeping of an accurate statistical record. Statistics of the magnitude of those I have brought forward can only be compiled and are only of value if absolutely reliable data of every case are available. In addition to the history sheets, which are carefully filled up and contain all the necessary details of the disease and treatment, we use a statistical card index of our own design, with a system of subdivision according to the site of the growth and by years. Every patient has her own card, and the details of every patient are filled in in alphabetical order. In this way we can maintain continuous supervision over the whole of our material, keep constantly up to date, and produce statistics of scientific value.

\section{CAN Radiotherapy be Improved?}

I will end my paper by putting a third question: Has the radiotherapy of uterine carcinoma reached the limits of its effectiveness, or is it possible to improve our results still further? This question is of practical importance to-day. The improvement of the efficacy of radiotherapy rests on two important groups of factors-direct and indirect.

The direct factors include all measures, mediate and immediate, for increasing the sensitivity of the growth to radiation. It is known that certain histological forms of uterine carcinoma, such as carcinoma adenomatosum of the cervix, seem to be less sensitive to radiation than others. The treatment of these includes all attempts to compensate for their lesser sensitivity by the local application of sensitizing media, including all local methods of reinforcing the radiotherapy-for example, fulguration and electrocoagulation.

The indirect factors include public and scientific propoganda to secure the early diagnosis of uterine carcinoma, and thereby to improve the quality of the clinical material. They also include the administrative measures which I have described, and every kind of auxiliary treatment directed towards improving the patient's general condition and counteracting the strain which any radiation treatment must impose on it. This is the object of the after-treatment. The improvement of the quality of the material seems to us to offer the best prospects of improving the results of radiotherapy. 
It is the experience of every exponent of radiotherapy, which he can confirm every day, that the patients who come to him to be treated for carcinoma of the uterus are extraordinarily bad material. This is borne out by our own figures: out of 1,723 cases of carcinoma of the cervix only 326 , or 18.8 per cent., fell into Group 1 (operable). The reason is not that radiotherapists assess their material by a more exacting standard than surgeons, but that the large radiotherapeutic institutions admit all the cases that have been given up at a glance as hopeless subjects for operation or any other kind of treatment.

The figures of operability for the patients treated by radiotherapy for carcinoma of the cervix fluctuate between 15 and 28 per cent. In contrast to these, clinics which still practise operation give figures of 40 to 80 per cent., and for carcinoma of the body of the uterus as high as 100 per cent. The handicap which these low operability figures impose on radiotherapy can be illustrated by a simple calculation from our figures. If 40 per cent. of our material were operable the absolute cure rate by radiotherapy would be raised from 24 to 30 per cent., and if 60 per cent. of the material were operable it would be raised to 40 per cent. The way to improve the material is suggested by one of the directions which Regaud has put forward for the work of the Radiological Commission:

" The encouragement of public and scientific propaganda directed towards the early recognition of carcinoma, so that early and effective treatment may be carried out."

\section{Conclusion}

I have endeavoured to explain within the scope of my paper: (1) what radiotherapy of uterine carcinoma, unassisted by surgery, can do nowadays ; (2) the conditions of technique, system, and administration under which these results can be achieved; and (3) the prospects, according to our experience up to date, of improving our results. The figures show unequivocally that radiotherapy can do all that operation can and more, in that it can cure inoperable cases. Moreover, they prove the truth of Döderlein's words :

"I have long maintained that the day of the dangerous and drastic radical operation is over."

Success depends, however, on possessing the proper means and using them in the proper way.

\section{RESULTS OF THE TREATMENT OF CANCER OF THE CERVIX UTERI* \\ BY}

\section{A. LACASSAGNE, M.D.}

SCB-DIRECTOR, PARIS RADIUM INSTITCTE

The subject with which I have to deal consists of certain data concerning the results which may reasonably be expected nowadays from the radium treatment of cancer of the uterus. Since I have the honour of addressing you as representative of the Institut du Radium de Paris, you will perhaps excuse me if I confine myself in this short survey exclusively to the statistics of the therapeutic section of that institution, of. which Dr. Regaud is the head. We consider that, in practice at least, the epitheliomata of the corpus and the sarcomata of the uterus belong to the domain of surgery, while the epitheliomata of the cervix are for the most part the province of radiotherapy ; it is with this class of cancers alone that I am concerned to-day.

Table I shows the total number of patients treated at the Institut du Radium de Paris by the staff of the Fondation Curie by radiotherapy, either alone or in combination with other treatment, between the years 1919 and 1926 . They numbered 678, of whom 182 (26 per cent.) were alive and free from all symptoms of cancer five years after the date of treatment. The percentage of cures varies, however, from year to year, suggesting a constant improvement which is chiefly to be explained by the regular progress that has been achieved in radiotherapeutic technique.

\section{Advances in Technique}

From the point of view of technique, the eight years under review fall into three distinct periods. The first, which comprises the years 1919 and 1920, just after the treatment department of the Institut Curie was opened, was a period of initiation and testing out of the medical personnel. Cervical cancers were irradiated with material that was not properly adapted to its purpose, and by diverse methods which subsequent experience has led us

* Translation of a paper read in opening a discussion in the Section of Obstetrics and Gynaecology at the Centenary Meeting of the British Medical Association, London, 1932 to regard as defective. The results were frankly bad: 10 and 17 per cent. only of cures. In 1921 we instituted our technique of introducing radium into the uterine cavity, and have not appreciably modified it since ; it is still given systematically in every case. It consists in the introduction into the uterus of a sound containing tubes of radium placed end to end in suficient number to fill up the whole length of the uterine canal; an arrangement is employed in the vagina by which tubes are held

TABLE I.-Comprehensive Statistics of Cases treated by Radiotherapy (alone or combined) Compiled at the End of the Fifth Year atler Treatment

\begin{tabular}{|c|c|c|c|c|c|c|c|}
\hline \multirow[b]{2}{*}{ Years } & \multirow{2}{*}{ 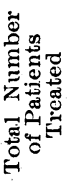 } & \multicolumn{4}{|c|}{$\begin{array}{l}\text { Patients Not Cured or Considered } \\
\text { as Such }\end{array}$} & \multirow{2}{*}{$\begin{array}{l}\text { Patients } \\
\text { found } \\
\text { Cured at } \\
\text { the End } \\
\text { of the } \\
\text { Fifth } \\
\text { Year }\end{array}$} & \multirow{2}{*}{$\begin{array}{l}\text { Percen- } \\
\text { tage of } \\
\text { Cures }\end{array}$} \\
\hline & & $\begin{array}{l}\text { Dead from } \\
\text { Cancer or } \\
\text { with } \\
\text { Recurrence }\end{array}$ & $\begin{array}{c}\text { Dead from } \\
\text { Inter- } \\
\text { current } \\
\text { Disease }\end{array}$ & $\begin{array}{c}\text { Lost } \\
\text { Sight } \\
\text { of }\end{array}$ & Total & & \\
\hline 1919 & 103 & 85 & 2 & 5 & 92 & 11 & 10 \\
\hline 1920 & 98 & 78 & 1 & 2 & 81 & 17 & 17 \\
\hline 1921 & 48 & 35 & 1 & - & 36 & 12 & 25 \\
\hline 1922 & 69 & 50 & 1 & - & 51 & 18 & 26 \\
\hline 1923 & 85 & 55 & - & 4 & 59 & 26 & 30 \\
\hline 1924 & 80 & 48 & 3 & 1 & 52 & 28 & 35 \\
\hline 1925 & 97 & 60 & 3 & - & 63 & 34 & 35 \\
\hline 1926 & 98 & 56 & 4 & 2 & 62 & 36 & 36 \\
\hline Totals & 678 & - & - & - & 496 & 182 & $\left(\begin{array}{c}\text { Mean } \\
\text { of } \\
\text { cures }\end{array}\right\}$ \\
\hline
\end{tabular}

round the cervix. The tubes used number from five to eight, have a wall thickness of 1 or $1.5 \mathrm{~mm}$. of platinum, and contain a total quantity of about 60 to $70 \mathrm{mg}$. of radium element: the total dosage from a continuous application lasting five or six days rarely exceeds 8,000 mg.-hours. Nearly all the cases treated in 1921, 1922 , and 1923 received this intrauterine treatment alone. Though inadequate, it was correct, and its merits are apparent in the increase in the rate of cure first to 25 per cent. and then to 30 per cent.

The staff then became convinced of the necessity of reinforcing the treatment by external irradiation, exerting 